\section{SÓCRATES E O PALHAÇO \\ Uma proposta de reflexão}

\author{
SOCRATES AND THE CLOWN \\ A proposal for reflection
}

Clara Rosa Cruz Gomes ${ }^{1}$

\title{
Resumo
}

Os elementos de teatro encontrado na figura do palhaço podem tornar o processo educativo mais estimulante e criativo, entretanto eles são pouco usados na prática. Um dos motivos que explica essa limitação é a falta de reflexão entre as figuras teatrais com o processo de educação. Esse artigo relaciona a figura do palhaço com elementos clássicos da filosofia grega, especificamente representado pelo pensamento de Sócrates e se faz uma reflexão que pode ajudar no processo educativo e da construção do artista cênico. A semelhança entre o pensamento de Sócrates e a figura do palhaço é construída com base em alguns elementos: a máscara; a justiça; e o Eros. A máscara seria a dissimulação do papel que se representa socialmente e aproxima Sócrates e a figura do palhaço. Depois ressaltaremos a constante busca por justiça que seria uma busca de ambos e através de Eros descreveremos a relação amorosa que ambos representam. Essa comparação entre Sócrates e o palhaço traz valores de justiça e amor que são importantes para o aprendizado dialógico e seria de fundamental importância para o educador de teatro.

Palavras- chave: filosofia, teatro, educação.

\section{Resumen}

Elementos de teatro en la figura del payaso pueden hacer el proceso más estimulante y creativo en educación, sin embargo son poco utilizados en la práctica. Una de las razones que explica esta limitación es la falta de reflexión entre las figuras teatrales con el proceso educativo. Este artículo enumera la figura del payaso con elementos clásicos de la filosofía griega, representado especialmente por el pensamiento de Sócrates y hacer una reflexión que puede ayudar en el proceso educativo y la construcción del artista escénico. La similitud entre el pensamiento de Sócrates y la figura del payaso se construye sobre la base de algunos elementos: la máscara; Justicia; y el Eros. La máscara sería el papel que disimula lo que se representa socialmente y aproxima Sócrates y la figura del payaso. Después se ressalta la constante búsqueda de la justicia para ambos y a través de Eros describir la relación amorosa que ambos representan. Esta comparación entre Sócrates y el payaso aporta valores de justicia y amor que son importantes para el aprendizaje dialógico y serían de fundamental importancia para el educador de teatro.

Palabras clave: filosofía, teatro, educación.

\section{Abstratc}

Theater elements that are associated with the figure of the clown can make the educational process more stimulating and creative, however they are rarely used in practice. One of reasons for this

${ }^{1}$ Clara Rosa Cruz Gomes é Mestre em Educação e Bacharel em Interpretação Teatral ambos pela Universidade de Brasília. Possui Licenciatura Plena em Educação Artística pela Faculdade de Artes Dulcina de Moraes. Atualmente, é Professora de Artes da Secretaria de Educação do GDF. Realiza pesquisas nas áreas de manifestações dramáticas e cultura popular brasileira; linguagens teatrais e ensino de teatro. Publicou o livro do seu mestrado Caminhos do Riso pela Editora Claridade em 2012. 
scarcity is the lack of studies that link thetrical figures with the education process. This article relates the figure of the clown with elements of Greek philosophy, particularly the thought of Socrates and describes how this reflection can help in the educational process and the construction of scenic artist. The similarity between the though of Socrates and the figure of the clown is elaborated with base in the elements: the mask; Justice; and Eros. The makes is the dissimulation of the role someone presents socially and links Socrates thoughts and the figure of the clown. Furthermore we will highlight the contant pursuit of justice that is typical of both characters. Finally, we will describe, with connection to Eros, the love relationship that is associated with both of them. This comparison between Socrates and the clown attempts to link the values of justice and love to the dialogic learning and plays fundamental role to the educator in theatre.

Keywords: philosophy, theatre, education.

Para Hadot filosofo estudioso de Sócrates há muita dificuldade em se definir a figura de Sócrates que é filósofo da antiguidade, e foi importante para construção do pensamento ocidental. Os estudos nos revelam sua feiura física. Descreve-se que tudo nele era excessivo, bufão, caricatural. Sócrates poderia ser comparado a figura do bufão ou do palhaço por representar a negação da cultura, e o aspecto grotesco e libidinoso dos instintos.

O aspecto monstruoso de Sócrates, a aparência feia é apenas uma fachada, uma máscara. Depois da feiura a simulação. "Sócrates se mascara a si mesmo. Isto seria a famosa ironia socrática. Sócrates finge a ignorância e a impudência ...ele se faz de ingênuo e infantil com as pessoas.” (HADOT, 2012, p.11). Ele se mascarou para a história. Sócrates ainda se serviu de máscara para aqueles que falaram dele.

Sócrates se assemelha a figura do palhaço. O palhaço também se mascara a si mesmo. O palhaço representa o marginal, aquele que por não ter nada a perder ou ser o perdedor, brinca com as instituições e os valores oficiais. Ele brinca, saindo dos padrões e das regras sociais presentes nos traços físicos e psicológicos que o caracterizam e isso lhe dá o poder de zombar de tudo impunemente.

O bufão é um ancestral do palhaço. O palhaço seria um herdeiro do bufão porque também pode ser considerado um marginal. As características e comportamentos do bufão aparecem no clown, mas de maneira tênue. O bufão representa o sujo, o feio, o marginal. O bufão carrega e revela a dor da humanidade em suas deformações e caracterizações. Para Burnier, ator, pesquisador e fundador do grupo de teatro Lume, "o bufão é um ser marginal e marginalizado. Ele tem deformações físicas [...] Essas deformações são como a somatização das deformações humanas interiores, das dores da humanidade [...] O bufão é grotesco. É malicioso e ingênuo, puro e cruel, romântico e libidinoso.” (BURNIER, 2001, p. 216). 
Sócrates e o palhaço abandonam os padrões sociais da beleza, da riqueza, do poder e os relativiza. Ele pode ser lírico, inocente, ingênuo, angelical, frágil e essas energias/emoções podem estar presentes em seus corpos.

\section{Máscara e o palhaço}

Por um mecanismo de proteção Sócrates utilizou a máscara, que seria a ironia socrática, a dissimulação utilizada para se poder interrogar e se fazer criar novos conhecimentos "porque se mascara a si mesmo, Sócrates tornou-se a máscara, de personalidade que tivera necessidade de se proteger atrás dela. Ele lhes deu ao mesmo tempo a ideia de se mascarar e a de tomar como máscara a ironia socrática.” (HADOT, 2012, p.11). A máscara introduz o ensinamento filosófico do pensar e a tomada de consciência. "A ironia do Sócrates levava seus interlocutores, por hábeis interrogações, a reconhecer a ignorância deles, a colocar em questão toda a sua vida." (HADOT, 2012, p.11). No auge do diálogo quando esse corre o risco de romper Sócrates toma para si a perturbação, a dúvida, essa seria a aventura da dialética. Transfere a Sócrates a inquietação e assim continua a construção da dialética. Aqui Sócrates assume ser o bode expiatório, aquele que assume para si o papel do outro. O palhaço assume ser o bode expiatório da sociedade, aquele que irá representar as mazelas humanas, as injustiças sociais, o vagabundo, o pobre, a fome, o perdedor.

O palhaço apresenta uma lógica que foge aos padrões convencionais. O nariz vermelho utilizado pelo palhaço seria sua máscara protetora. O nariz vermelho pode ser considerado a menor máscara do mundo. O nariz do palhaço tem um formato circular "em sua qualidade de forma envolvente, qual circuito fechado, o círculo é um símbolo de proteção, de uma proteção assegurada dentro de seus limites" (CHEVALIER, 1999, p. 254). Com essa máscara o palhaço se sente protegido para se expor e se revelar. O nariz apresenta cor vermelha, o que evidencia grande emoção. "A cor vermelha leva em si os dois mais profundos impulsos humanos: ação e paixão, libertação e opressão." (CHEVALIER, 1999, p. 946). O nariz vermelho permite ao palhaço expressar livremente e poder ser ridículo. Neste nariz se encontra a ironia socrática.

Em geral, para se conseguir a máscara do palhaço torna-se preciso passar por um processo iniciático. A origem do uso de máscaras pelo homem se relaciona a cultos sagrados e rituais religiosos. Para Burnier, o clown passa por algo parecido, vivencia um processo particular, difícil e doloroso que lhe imprime uma identidade.

A máscara do palhaço, pela identidade com a manifestação que essa figura representa, seria para o ator o próprio objetivo de representação. Essa máscara se caracteriza como libertadora e 
pode operar como catarse. "A máscara não esconde mas revela, ao contrário, tendências inferiores, que é preciso pôr a correr. Nunca se utiliza nem manipula a máscara impunemente" (CHEVALIER, 1999, p. 596).

A máscara do palhaço exigiria cuidados especiais e o uso de conhecimento de técnicas para quem a utiliza. Muitas culturas que utilizam máscaras também alertam para esse cuidado; "as máscaras da dança do trot são objeto de cuidados especiais; caso contrário, seriam perigosas para os portadores" (CHEVALIER, 1999, p. 596).

Sobre as divindades grotescas e engraçadas que aparecem em rituais de diferentes culturas, Campbell filosofo contemporâneo estudioso dos mitos, aponta para o fato de essas figuras fazerem olhar para além delas. Elas mostrariam as imperfeições e a própria vulnerabilidade: “eu não sou a imagem última, deixo transparecer alguma outra coisa. Olhe através de mim, da minha forma engraçada" (CAMPBELL,1990, p.229) Essas figuras se assemelham à figura do Sócrates e do palhaço. As máscaras utilizadas pelos iroqueses apresentam a criação falha e representam o papel de cura, "sua função é essencialmente médica; elas preveem e curam tanto as doenças físicas como as psíquicas. Nos ritos praticados, os homens mascarados representam a criação falha: anões, monstros, etc.”. (CHEVALIER, 1999, p. 596). A função da máscara se relacionaria com uma possível busca de consciência.

Percebe-se um papel social na utilização das máscaras quando elas fazem o homem perceber o seu lugar no universo ao participar de um drama coletivo. "As máscaras preenchem uma função social... são também verdadeiros espetáculos catárticos, no decurso dos quais o homem toma consciência de seu lugar dentro do universo, vê a sua vida e a sua morte inscrita em um drama coletivo que lhes dá sentido." (CHEVALIER, 1999, p. 597).

A máscara é identificada como mediadora entre duas forças: uma que se identifica com a aparência do que ela representa e a outra, com o portador que a manipula. "A máscara e seu portador se alternam e a força vital que está condensada dentro da máscara pode apoderar-se daquele que se colocou sob a sua proteção.” (CHEVALIER, 1999, p. 597). A máscara pode colocar o ator em contato com uma realidade profunda; "o ator que se cobre com uma máscara se identifica, na aparência [...] com o personagem representado" (CHEVALIER, 1999, p. 597).

Para ser palhaço e para construir a ironia socrática há necessidade de inteligência e maturidade para saber a hora de cumprir o seu papel social. "Todo o espírito profundo precisa de máscara e mais uma máscara se forma perpetuamente em torno do espírito profundo graças a 
interpretação falsa, rasa, dada as palavras, as suas trajetórias, a todas manifestações de sua vida." (HADOT, 2012, p.15).

Sócrates traz consigo o sedutor, o educador, o condutor de almas. A máscara socrática é a máscara da ironia, da dissimulação, nos quais aparece a palavra grega eironeia. A ironia é uma atitude psicológica na qual o individuo busca parecer inferior ao que ele é, ele se autodeprecia. Assim, fingi dar razão ao interlocutor a fingir adotar o ponto de vista do adversário.

Uma ironia do palhaço parecida com a socrática está na figura do bobo que não sabe de nada é uma figura que também carrega a inocência. A inocência se relaciona com a ingenuidade que aparece em sua simplicidade, franqueza e sinceridade. Os palhaços apresentam uma ingenuidade enganadora. Para Freud, pai da psicanálise, essa ingenuidade apresenta as atitudes "como ingênuas de modo a poder desfrutar uma liberdade que de outra forma não lhe seria permitida" ( FREUD, 1996, p. 174) . Clarissa Pinkola Estés, psicanalista junguiana, descreve que "ser inocente significa ser capaz de ver com nitidez qual é o problema e corrigi-lo." (ESTES, 1994, p. 193). O ingênuo se tornou assim pela experiência, diferente daquele que é alegre por não saber de nada. "A inocência é uma atitude não só de evitar o dano aos outros, mas também a capacidade de curar a si mesma.” (ESTES, 1994, p. 193).

O bobo tenta em sua ingenuidade enganadora indicar os limites. O bobo contrapõe ao poder e seria o alívio de toda espécie de repressão e tensão através das pilhérias. "O bobo lembra ao rei que ele é mortal, para evitar a embriaguez do poder solitário [...] O bobo é a contrapartida à exaltação do poder porque ele é o único que pode dizer tudo ao rei. Sob a proteção da loucura e, portanto do riso, ele pode dizer tudo. A verdade passa a ser a loucura do riso.” (MINOIS, 2003, p. 231). O humor e a ironia presentes na figura do palhaço e do Sócrates são atitudes permitidas com a relatividade das coisas, saindo da rigidez e do fanatismo e em busca da construção conjunta do conhecimento.

Sócrates declarava nada saber: "fala, discute, mas se recusa a ser considerado como mestre... ele aceitava com prazer não ser ele próprio notado.” (HADOT, 2012, p.17).

O significado da ironia socrática: Sócrates percorre o caminho dialético com seu interlocutor sem ele saber. Esta aí a ironia, a dissimulação. "Sócrates é parteiro dos espíritos... ele nada sabe então ele ajuda os outros a engendrar a si próprios... Ser mestre é verdadeiramente ser discípulo.” (HADOT, 2012, p.20). 


\section{Justiça e o palhaço}

Sócrates é apaixonado pela palavra e pelo diálogo. Na falta da palavra fazia ver o que é justiça pelos seus atos.

A Justiça seria a virtude que traria a harmonia e a concórdia. A Justiça, sendo uma virtude completa, compõe todas as outras e compreende a inteligência, a prudência, a coragem, a fidelidade, a generosidade, a tolerância. É fundamental "resistir antes de tudo à injustiça que cada um traz em si mesmo. É, por isso, que o combate pela justiça não terá fim." (COMTESPONVILLE, 1999, p. 95).

A inspiração do palhaço pode nascer de alguma dor, de algum sofrimento ou de algum desespero. Para o filósofo francês contemporâneo Comte-Sponville, que estuda as virtudes, a coragem se dá "quando não há mais nada a esperar, não há mais nada a temer: eis toda a coragem disponível, e contra toda esperança, para um combate presente, para um sofrimento presente, para uma ação presente" (COMTE-SPONVILLE, 1999, p. 65). O palhaço pode trazer com ele alguma mensagem exemplar e fruto de um conhecimento experimentado que, através do riso, faça refletir sobre as dificuldades do próprio ser humano. O riso do palhaço e a ironia socrática pode ser um ato de coragem.

Nunca compreenderemos a justiça se não a vivermos. Como toda a realidade autêntica a justiça é indefinível. É precisamente o que Sócrates quer fazer seu interlocutor compreender ao convidá-lo a viver a justiça. Tentando persuadi-lo de se preocupar menos com o que tem mais do que com o que é. Ele faz pensar sobre nossa existência. Ele é o que deseja sabedoria porque dele está privado. Sócrates só é sábio pela consciência de não ser sábio, pela sua ignorância.

O palhaço como Sócrates não é bonito, nem inteligente. O palhaço representa a sombra e pela coragem de se ver a sombra pode se chegar à luz, conseguir conhecimento e construir justiça.

Sócrates como o palhaço seria o eterno vagabundo em busca do conhecimento e da verdade. Destaco como palhaço Charles Chaplin que representa o vagabundo, o pobre, o excluído.

\section{Eros e o palhaço}

No livro $O$ banquete o filósofo grego Platão faz uma discussão e uma reflexão sobre o amor. Para Sócrates de Platão o amor aparece como sendo o desejo sempre de possuir o que é bom. Platão define Eros, o deus que representa o amor, dentro da dualidade da pobreza e da riqueza, de 
ter e de não ter, de saber e de não saber. O amor parece ser uma busca de algo que falta e que se não possui.

Para o filósofo francês contemporâneo Comte-Sponville , Platão escreve o amor como sendo "não perfeição plena, mas pobreza devoradora. É o ponto decisivo de que devemos partir. Ele cabe numa dupla definição: o amor é desejo e o desejo é falta [...] o que não temos, o que não somos, eis os objetos do desejo e do amor.” (COMTE-SPONVILLE, 1999, p. 253).

No amor estaria presente o riso já que existe nele a felicidade, uma alegria prazerosa de encontro e realização, a alegria de amar e de ser amado. A tristeza poderia ser pela falta de amor.

\begin{abstract}
O amor pode ser frustrado, sofrer, estar de luto mas o amor está na alegria, mesmo que ferida, mesmo que amputada, mesmo que atrozmente dolorosa quando a magoam e não nessa ausência que a dilacera. Não é o que me falta que eu amo; o que eu amo é que, às vezes, me falta [...] Adeus Platão [...] considerando o amor em sua essência não há amor infeliz. (COMTESPONVILLE, 1999, p. 272).
\end{abstract}

$\mathrm{O}$ amor poderia ser a integração do próprio ser e o respeito mútuo às diferenças. $\mathrm{O}$ sofrimento, no amor, acontece talvez por se querer tornar único algo que supõe a dualidade, a diversidade e o outro. $\mathrm{O}$ amor poderia ser construído com respeito às dualidades em uma relação de amizade, em que estaria presente o diálogo, numa tentativa de encontrar harmonia, numa relação de igualdade na qual não haveria submissão.

O opressor perverte o sentido de amor e escraviza o oprimido, anulando toda a sua vontade, todo o seu desejo e o seu poder de decisão e de realização. "Quando o amor é pervertido, ao invés de ser o centro unificador buscado, torna-se o princípio da divisão e da morte. Sua visão consiste em destruir o valor do outro, numa tentativa egoística de escravizá-lo." (CHEVALIER, 1999, p. 47). A ironia socrática resgata o poder perdido.

Zigmunt Bauman, sociólogo polonês da atualidade, compara o amor a sociedade de consumo quando fala que até o amor virou uso de consumo e descarte. "Vínculos e liames tornam 'impuras' as relações humanas- como fariam com qualquer ato de consumo que presuma a satisfação instantânea e, de modo semelhante, a instantânea obsolescência do objeto de consumo. “ (BAUMAN, 2004, p.65).

O Eros no Sócrates e no palhaço pode vir mostrar um outro sentido de amor, o de “enriquecer o outro e a si mesmo por meio de uma doação recíproca e generosa que faz com que ambos cresçam, tornando-se ao mesmo tempo, cada vez mais eles-próprios. [...] O erro fundamental no amor é que uma parte se tome pelo todo" (CHEVALIER, 1999, p. 47). Segundo Bauman, para 
termos amor-próprio precisamos ser amados. "O amor-próprio é construído a partir do amor que nos é oferecido por outros (...). Outros devem nos amar primeiro para que comecemos a amar a nós mesmos.” (BAUMAN, 2004, p.100). E assim se constrói Eros na figura do Sócrates e do palhaço. Eles são buscadores do amor.

A clássica dupla do palhaço mostra a relação entre os palhaços branco que representa o opressor, o poder, o que pensa ser perfeito e o palhaço augusto que representa o oprimido, o tonto, o que faz tudo errado.

A relação de amor entre oprimido e opressor, seria um falso amor, visto que eles não encontram a felicidade. Esse amor parece se criar pela ignorância visto que o oprimido não conhece possibilidades para ser feliz. Para ser construído um verdadeiro amor seria preciso de igualdade nas relações e ninguém ser superior ou inferior a ninguém. Seria querer a superação de todo o sofrimento. Precisaria haver algum conflito para a construção do amor, porque as relações foram construídas pela força e pelo poder de dominar o outro. Esse conflito poderia se dar pela tentativa desesperada de ser feliz.

Amor educador do palhaço e de Sócrates seria como afirma Comte-Sponville "é ridículo levar-se a sério. Não ter humor é não ter humildade, é não ter lucidez, é não ter leveza, é ser demasiado cheio de si, é estar demasiado agressivo, é quase sempre carecer de generosidade, de doçura, de misericórdia" (COMTE-SPONVILLE, 1999, p. 253).

A ironia amorosa de Sócrates consiste em fingir estar enamorado. O pretendido como tal descobre pela atitude de Sócrates que é incapaz de satisfazer o amor pois não tem em si a verdadeira beleza.

O palhaço e o Sócrates parece uma figura contrária à narcisista. A figura narcisista representa culto exacerbado ao perfeito, ao belo e ao consumo. Lipovetski, filósofo francês e pensador crítico sobre a contemporaneidade, define o narcisismo como "o surgimento de um perfil inédito do indivíduo nas suas relações consigo mesmo e com o seu corpo, com os outros, com o mundo e com o tempo no momento em que o capitalismo autoritário cede lugar a um capitalismo hedonista e permissivo". (LIPOVETSKY, 2005, p. 32.) O palhaço revela o feio, a fome, a miséria, a simplicidade e talvez, por isso, traga consigo uma profunda esperança e transformação.

Para o sociólogo francês contemporâneo Baudrillard, há toda uma economia dirigida para esse culto narcisista. "Esse neonarcisismo está ligado à manipulação do corpo como valor. Trata-se de uma economia dirigida do corpo.” (BAUDRILLARD, 1996, p. 150). O palhaço 
ridiculariza o belo, o perfeito, a arrogância trazida nessa sociedade por ser uma figura que parece se tornar estranha a tudo isso.

Descobrindo o que falta se pode enamorar por Sócrates ou pelo palhaço mas isto não é pela beleza pois Sócrates não a tem, mas pelo amor que é. Assim estar enamorado por Sócrates ou pelo palhaço é estar enamorado pelo amor.

O essencial não se situa nas aparências, no costume ou no conforto mas na liberdade. A liberdade de ser, de descobrir o ser, de expressar o ser. Isso é um grande desafio que se conquistado se pode descobrir sua originalidade e humanidade.

Eros socrático e do palhaço é uma força que não é nem divina, nem humana, nem diabólica, nem angelical; que separa e que une todos os seres. Elemento ambíguo, ambivalente, indeciso, não é nem bom e nem mal. No riso provocado pelo palhaço e na construção de conhecimento de Sócrates estão presentes esses elementos.

O Sócrates como representação da figura do palhaço pode ser considerado como o sábio do coração. Sócrates teria a delicadeza e a leveza de suavizar, de reaquecer, cuja voz sabe descer até o mundo subterrâneo e sombrio e trazer luz. Sabe silenciar os barulhentos e os soberbos e ensinalhes a escutar construindo uma relação dialógica, "renovado aos seus próprios olhos acariciado e desnudado pelo sopro morno do degelo talvez mais vulnerável, mais frágil, mais quebradiço, cheio de esperanças que ainda não tem nome.”(HADOT, 2012, p.48.)

\section{Referências}

BAUDRILLARD, Jean. A troca simbólica e a morte. São Paulo: Loyola, 1996.

BAUMAN, Zygmunt. Amor Líquido: sobre a fragilidade dos laços humanos. Rio de Janeiro: Jorge Zahar,

BURNIER, Luís. A arte secreta do ator: da técnica à representação. Campinas, SP. Editora da Unicamp, 2001.

CAMPBELL, Joseph. O poder do mito. São Paulo: Athena, 1990.

CHEVALIER, Jean; GHEERBRANT, Alain. Dicionário de símbolos. Rio de Janeiro: José Olympio, 1999.

COMTE-SPONVILLE, André. A felicidade, desesperadamente. São Paulo: Martins Fontes, 2005. O ser-tempo. São Paulo, Martins Fontes, 2000. 
Pequeno tratado das grandes virtudes. São Paulo: Martins Fontes, 1999.

ESTES, Clarissa Pinkola. Mulheres que correm com os lobos. Rio de Janeiro: Rocco, 1994.

FREUD, Sigmund. Os Chistes e sua relação com o inconsciente (1905) (Edição Standart Brasileira das obras psicológicas completas de Sigmund Freud.) v. 8. Rio de Janeiro: Imago, 1996.

HADOT, Pierre. Elogio de Sócrates. São Paulo: Edições Loyola, 2012.

LIPOVETSKY, Gilles. A era do vazio: ensaio sobre o individualismo contemporâneo. Barueri, SP: Manole, 2005.

MINOIS, Georges. História do riso e do escárnio. São Paulo: Unesp, 2003.

PLATÃO. O banquete. São Paulo: Rideel, 2005.

Recebido em 05/09/2014

Aprovado em 06/11/2014

Publicado em 13/01/2015 